\title{
Criminal Intelligence Management System and Security in Kenya: A Case Study of Kirinyaga County
}

\author{
Njiru Lemmy Wanjau \\ Department of Security and Correctional Science, Kenyatta University \\ Dr. Stephen Handa \\ Department of Security and Correctional Science, Kenyatta University
}

\begin{abstract}
Law enforcement agents require Criminal Intelligence about their immediate and that of the wider environment in which they operate in order to guarantee their safety and that of others, they need to keep track of internal and external threats. It is a combination of these internal and external threats that develop the concept of security. The purpose of this study was to look at Criminal Intelligence management system and security in Kenya. The objective of the study was to; assess the extent to which integrated criminal intelligence management system is used in Kenya. The study targeted Kirinyaga County from where the findings were realized. The study employed a descriptive survey design targeting various levels of Intelligence Management in Kirinyaga County. The levels comprised of County, Sub county and Ward security and intelligence committees. The Total target Population of the group was 79 people. However, for practical reasons the research sampled 55 persons. An interview schedule and individual questionnares were used to collect data. Prior to engaging in actual data collection a pilot study was carried out in Kiambu County which had population with similar characteristics with Kirinyaga county to test validity and reliability of the instruments. Data collected was analyzed both quantitatively and qualitatively. The data was then described in statistics from where it was captured in frequencies and percentages arrived at through excel computer package. The results were then presented using tables and charts from where the discussions were based and findings drawn. The finding from the study revealed that criminal intelligence management system did not have proper control mechanisms to gather actionable information to be able to fully curb crime. Other findings were that the system was riddled with some challenges which included lack of trust among the various agencies, bureaucracies in disseminating the intelligence to the operations teams among others. The main recommendation of the study is that there is urgent need to put in place criminal intelligence plan detailing information gathering, collation and sharing, proper vetting and joint training of all the officers handling intelligence be undertaken so as to achieve synergy at various levels and have enabling legislations to address issues of autocracy.
\end{abstract}

Keywords: Criminal Intelligence, Management System, Security

DOI: $10.7176 /$ PPAR/11-8-04

Publication date:October $31^{\text {st }} 2021$

\subsection{Background of the Study}

According to the American National Criminal Intelligence Sharing Plan (2001), identification of the limitations in intelligence proceses which may have led to the events of September 11, the summit advocated for all enforcement agencies to fully participate in coordinating, collecting, analyzing and disseminating criminal intelligence information to make the nation safer. This saw the creation of a council to coordinate Intelligence information as well as promote and ensure effective sharing while addressing problems that inhibit the processes.

According to Zinn 2010, the key barriers identified as hindering the intelligence process by the Council were the hierarchical nature of law enforcement entities and their intelligence counterparts, redundant policies hindered access to information and lack of channels which supported information sharing.

The advanced democracies such as Britain and United States have managed intelligence systems to successfully decrease crime Els (2000). In United Kingdom calls for effective and efficient Management of Intelligence systems emerged as a result failure by traditional policing systems to adapt with the rapidly changing environment occassioned by the aspects of globalization (Carter 2009). The author argues that globalization witnessed an upsurge of international and cross border crimes. This was due to eradication and opening up of barriers across the globe. An audit of Police oversight in Africa report of 2008 recommended that police need to maximize resources, integrate with other law enforcement agents and have a greater focus to tackling crime and criminals. This was only possible by proper utilization of intelligence material.

In Australia the use of crime intelligence products like monitoring and analysing the crime patterns as well as the Police Station crime profiles helped greatly in identifying crime hot zones and probable culprits and their agents (Maree 2007). Australia embraced structures of accountability from the community level, consolidated both units of intelligence and investigation. They went beyond to target daily police operations by disseminating timely intelligence reports (Ratcliff, 2003). Ratcliff further states that performance outcome reviews were incorporated in crime assessment within Australian jurisdictions. 
In Africa region, South Africa is increasingly coming up with strategies to suppress crime and stigma associated with crime through effective management of criminal intelligence. This is following the disbandment of Bureau of State security (BOSS). According to O'Brien, BOSS had the functions which entailed collection of information, evaluation, collating and proper interpretion of security related data. This kind of arrangement witnessed lots of conflict among various security agencies. It was largely viewed as collecting surveillance on antiapartheid individuals and oranizations. This gave rise to battle for supremacy brief with the South African Police as they fought for control and influence over political masters. This led to creation of crime intelligence unit established by law. Emphasis was on establishing a crime analysis and information capacity at Police Station level.

In Kenya security concerns emanate largely from individual criminals, community based conflicts, ethnic disputes, religious ideologies, as well as activities of organized criminal groups. To address these threats the National Intelligence Service(NIS) is expected to work together with the National law enforcement agencies to identify risks, threats or opportunities that a criminal element is likely to exploit, formulate a general expectation as they embark on information gathering, processing, collation and analysis. However, these threats remain rife.

The untamed criminal activities in Kenya is likely to be an indication of either ommission or commission by the state or its organs of law enforcement. This confirmation has been made on numerous instances in both electronic and print media. The Kenyan media from time to time show horrifying crime scenes and tell saddening stories regarding victims of rape, robbery, and murder on a daily basis. A case in point was reported via citizen bulletin of May 7, 2019 where twelve innocent persons were reported to have been hacked to death in Matungu by marauding gangsters.

United Nations crime surveys conducted in Kenya have confirmed the alarming crime rates . In a survey carried out in 2016, it revealed that more than half of the Kenyan population are worried of falling victims to crime. That another three quarters of the population do not feel safe within their homes and work places (UN - Habitat, 2016).

\subsection{Statement of the Problem}

Kenya being a global player has had a robust National intelligence agency which complements other security operational agencies. In order to address National security threats in Kenya, Intelligence Service (NIS) works together with the Police Service (NPS), Directorate of Criminal investigations (DCI) as well as the Kenya Defense Forces Directorate of Military Intelligence (KDF-DMI) to identify risks, threats or opportunities that a criminal element is likely to exploit.

This has however not significantly addressed the question of high crime rates in Kenya. Despite the existence of the law enforcement agencies and their concerted efforts to address security threats, the crime levels as reported through various sources has remained abnormally high and worrying as they keep on mutating. The concern is even worse when local police operational commanders complain that they do not get operational intelligence to assist with security operations while the National intelligence counter this. This calls for change of tactics by adopting an approach that emphasizes criminal intelligence management to mitigate security threats in Kenya. Many studies have been carried out regarding how the high crime levels can be addressed including the role of criminal intelligence and many others on intelligence led models of policing in fighting crime. However, limited studies exist in exploring how the holistic management of criminal intelligence System impacts on security in Kenya. This study therefore, aims at exploring the management system of criminal intelligence and the impact it has on security in country Kenya.

\subsection{Research Objective}

To explore the extent to which integrated criminal intelligence management system are used in Kenya.

\subsection{Research Question}

To what extent is the integrated criminal intelligence management system used in Kenya?

\subsection{Significance of the Study}

This study would be of immense importance first to the researcher of this project. This is through personal growth of research skills, proficiency and advancement of academic credentials so as to apply the skills in work environment. The Second significance is for academic reasons. Other researchers and academic institutions may find the information useful in furtherance of their research studies. Finally the study may be used by policy makers in the field of security to come up with strategies that ensure proper management of security intelligence for crime reduction. This may involve reducing conflict between security agencies and all related stakeholders as it make all feel part and parcel of the decisions made.

\subsection{Literature Review}

Theoretical underpinnings of th study, empirical literature as well as conceptual literature related to the study 
consturets are presented in this section.

\subsubsection{Theoretical Framework}

The study was underpinned by the Systems theory. Systems Theory, is a discipline of study which entails having a wholistic analysis of an organization. Through this discipline organizations are analyzed individually based on what and where they are located. It looks at various parts of an organization and how it contributes to the whole organizations greater objectives. (Hooper 2014). According to the theory every organization has some level of similarity with others in the universe regardless of its size or how complicated it operates. A scholar Von Bertalanffy suggested this theory in his attempt to unite various departments under one so as to provide a ground upon which issues relevant to the main goal were to be discussed and harmony created.

Based on the above introduction, its imperative that a system consists of several parts all which integrate to give rise to a larger entity. Just like a human body consists of atoms, different cells, tissues which in an interactive way to give the body as it is known. The key concept is on how parts keep on interacting to produce the whole.

In Law enforcement, there is need to exchange informantion among the agencies, trust amongst different sectors and need to adopt synergy among both the operations teams as well as the strategic levels. (Coleman, 2006). The author further asserts that, the entire phases of information sharing should have some harmony though out to point of disemination for objective realization.

Systems theory simply deals with analyzing and patterns that depict the entire oganization as defined by its elements. This calls for long term collaborative planning as well as having constant feedback on progress of different entities and components (thinking page 2015). This is the reason as to why this theory is considered most effective in dealing with complex organizations and complex issues where issues largely depend on actions of other people or elements. (Aronson, 2015). He further gives an example that given a case of accidents and their causes, its prudent to critically look at the causing factors by reexamining relationship among various actors and players.

\subsubsection{Empirical Review}

Literature on previous stydies related to the present study is presented in this section.

\subsubsection{Integrated Criminal Intelligence System}

Graham, a law-enforcement risk management expert, enough systems are ideal in security sectors because its through them that crucial concerns can be able to be identified and given priority. Karen et al, further asserts to this that such an approach to security is due to the fact that security and safety is a product of several sub components rather than of an individual entity. It is only by looking at Security in this broad dimension that actors can be able to identify any gaps and mishaps that may have arisen.

These arguments call for alteration and change the manner in which law law enforcement organs address the whole concept of security concerns. It calls for a broad lens which systematically analyzes the concept of security as a joint process and not which can be achieved by a single phase or individual office bearer. There is a general realization that based on this theory law enforcement units are unified and constitute an order whereby every unit has an influence on the overall outcome.

Its imperative to note that since security consists of a given sequence, the sectors involved must follow processes and procedures to be realized. It is not something that can be achieved through isolation. The processes giving rise to the final product which is intelligence should be attained as a single unsycronised system though consisting of several subsets.. It thus follows that crime and security Management in Kenya is a product of systems. It includes the Kenya National Intelligence service (NIS), Kenya National Police Service (NPS) and the Directorate of Criminal Investigations (DCI). All these organs Must work as a single entity and system be be able to realize the core mandate to which they are tasked.

The Law enforcement agents should work together in realizing the intelligence management cycle of planning, gathering of information, collation, analysis and dissemination. Planning is the determination of intelligence needs alongside developing the most appropriate infrastructure. It thus requires a joint plan of colletion of information, issuing of general directions and the final consumption by defferent agencies UNDOC (2011). It helps security in that it is the point where law enforcers express a requirement on collection and synthesis of criminals or their criminal activities. It is on this basis that both the client and analytic unit formulate a plan regarding risk areas, vulnerability levels which those collecting data should narrow down to (Ratcliffe 2017). The author further argues that Data Collection deals with gathering only relevant information towards combarting a specific crime. The key question at this phase is on how much that should be collected to meet each requirement. The aim needs to only be directed at developing and identfying an ideal source to gather information that should therefore be to develop the most useful sources and collect the information most likely to lead to accurate results. For example information should be relevant in identifying the criminal's associates as well as the roles each plays in executing these activities.

Once information or data has been collected, then it is processed. This is the stage where logic is drawn depending on quality of data obtained. (Allen 2008). This should be done with reasonable time from the point data is colleected so as to ensure that the analysis is done at a reasonable time and it remains relevent to the period the 
information was acquired. Data that has been verified is then collated. Ratcliffe (2017 The data is collated in a filing cabinet or stored in a computer data base in a format that is accurate and allows timely access. Allen (2010) states that information that is not relevant, not correct and which could not be usefull is discarded in a safe manner since it may contain very sensitive security information which must be protected.

According to UNDOC (2011) Personnel involved in data collation must be of unquestionable integrity, with no any affiliation or linkage with the target criminal since it may compromise the wholw process. The information is then secured under lock and key at all times and that no anauthorized person has access to the working area or the storage place. A criminal accessing this information is at an advantaged position over the enforcement officers thus may propagate the very criminal activities (Rand, 2011).

The sythesis and analysis phase is anothey integral stage. Allen (2012) describes this phase as a thorough scrutiny of all the information available so as to give the intended meaning. Such analysis shows any existing gaps in regard to information gathered, shows the strengths and weaknesses that would arise as well as suggesting the way forward. In crime control, it gives the roadmap upon which a criminal activity is to be addressed. UNDOC (2011) calls it the phase where the nature of criminal activity is revealed, the actors unveiled, strengths made known and their method of operation revealed. It is also the phase that recommends the appropriate strategies of countering the identified criminal activity. Once the gaps are identified and highlighted, the information is then disseminated. According to Rand, (2011) This is the maxim of intelligence process. It is the process of moving intelligence from producers (intelligence officers) to consumers (enforcers) (Lowenthal, 2010). Dissemination of analyzed information may be done through notes to targeted consumers, oral briefs regarding large and sensitive investigations and reports that detail the available information. This is a stage which advises law enforcers the choices available for action, with some projection of consequences from each action.

\subsubsection{Nature of Information}

Criminal intelligence entails an analysis of collected information and evaluating to produce products that can be used to support informed decision making (California Department of Justice, 1998). It simply entails a set of questions and evaluating the answers. It commences by exploring the given problem, identifying the available information and how to extract more to reveal the going ons and evaluating how the information affects the decisions about to be made. It thus requires classification of information gathered.

According to UNDOC, the information can be from open, closed or classified sources. Open source is information that is available to the public. It could include information from research, technical or economic reports, dissertations among others. Closed sources of information may include information that is collected for a specific purpose but which has limited access and availability to the general public. In intelligence, the databases could include personal data collected regarding operations or criminal records. Finally the classified information entails information collected by covert means such as human and technical resources.

In intelligence, all sources are employed. Its thus important to select useful information sources according to relevance and not according to ease of access if one is likely to produce accurate results. A major issue in collection of information could emanate simply from the language of the source. The kind of language used is also likely to affect the quality of analysis thereby having an effect on final product. The key question at this phase is on how much that should be collected to meet each requirement. The aim should be to identify and build on most relevant sources and use the best collection methods of information that produces accurate results. For example information should be relevant in identifying the criminal's associates and the specific tasks in the targeted criminal activities.

\subsection{Research Methodology}

Descriptive survey design was used to establish the effect of Intelligence management and security. Descriptive design aimed at collecting information in the natural settings where findings were reported. The methods used were both qualitative and quantitative research methods. This gave both non-numerical data and numerical data. A blend of these two methods gave rise to a corroboration of the effect of Intelligence management on Security in Kenya.

The location of the study was Kirinyaga County. This is a County with both urban and rural settings. The population mix gave an impression of the two extremes in respect to urban and rural crimes. This gave the reasearcher a wide range of security concerns which are applicable to both the rural and urban setups. According to the 2009 census the county had an urban population of about 90,000 people against a rural population of 445,627 . The two set ups are within an area of about $1,205 \mathrm{~km}^{2}$ the implication being that both urban and rural set ups are closely concentrated. According to Crime Research Centre most of the crimes committed within the County are in tandem with the figures given in the Police annual crime report 2018 which places the County as number 4 with a crime index of 409.

The security and intelligence committees were of interest to the researcher. This is because its at these levels that criminal intelligence is managed. Each security and intelligence committee comprises of 5 members namely the DCC, SCPC, CIPU, NIS and DCI. The researcher thus targeted all the 18 ward security and intelligence committees , 4 sub county security and intelligence committes ( Kirinyaga Central, East, south and west) and the 
County security and intelligence committee (Kirinyaga).

The researcher employed both probability and non probability sampling methods. The wards targeted had huge number of units to be studied thereby occassioning the use of probability sampling. A statistically valid sample size with a confidence level of $90 \%$ and a margin error of 5\%, a sample size of was ideal out of the target population of 90 . The 18 security ward committees all had an equal chance of being studied and accounted for 64 respondents. The sampling was purposeful in that only those members who manage Security intelligence participated. On the other hand, since composition of the Sub county and county security teams are defined, then, convinience and Purposeful sampling formed the basis of non probability sampling in this study. A total of 11 respondents were from the sub county and a further 4 from the county level. Due to the sensitive nature research assistant who understood the security operations and the terrain of the study area were recruited to help in the process.

Objectives of this study were best achieved by use of both questionnares and in-depth interviews. The questionnares were administered at individual level of the targeted respondents. The questionnaire were divided into 2 sections where section one delt with collecting bio data while section two was exploring the objectives of the study. The interviews were personal and majorly unstructured. This mainly targeted the County, Subcounty and ward commanders. This was aimed at getting deeper insight into the subject matter by reading the respondents verbal and non-verbal cues.

To test validity, researcher engaged experts in the field of security to assses the content validity. Secondly is that the researcher submitted the research instruments to the supervisor to ascertain whether the items posed were valid to answer the research questions and objectives. To improve on reliability the researcher used a test re-test design. The questionnare was administered twice to the same respondents and feedback gotten. All questionnaires were administered as a way of pre-test on a similar sample population to that which was targeted in the main research so as to assess the relevance and whether they were suitable. The Pretest sample which the researcher considered to have similar characteristics was in Kiambu County. The research questionnaires was given to targeted responders and thereafter picked for analysis by the researcher. Based on findings from the test-retest excersice, Cronbach's Alpha Coefficnet of reliability was compputed and releaved to be 0.811 . This was significantly higher that the 0.70 threshold that is used in behavioural sciences and implies that the research questionnaire was reliable.

Before analysis, data collected from the questionnares and interview guides was checked for clarity, completeness and consistency before being subjected to statistical analysis. Data for this research was analyzed using both discriptiuve and inferential statistics with the help of the Statstical Package for the Social Sciences (SPSS)vesion 23.0 for windows. All statisrtical measurs were conducted within $95 \%$ confidence interval.

\subsection{Research Findings}

Upon administration of the research instruments by the researcher and assistants, 55 instruments out of the targeted 79 were successfully filled and submitted back for analysis. This represented $69.6 \%$ success rate of the submitted forms. However, a challenge was noted in that some respondents held more than one office at the time data was collected.

The researcher targeted 79 respondents to participate in the study. This comprised of County Security Committee members, Sub County security committe members and ward security Committee members within Kirinyaga County. Out of the targeted group, 55 responses were duly completed and formed the basis of these results. This was equivalent to $69.6 \%$ which the researcher considered adequate for the study as it gave a good representation of the target population. The return late was below the researchers target largely because of what was noted to be deficiency in staffing. Most of the respondents held more than one jurisdiction thereby affecting the targeted respondents. Interviewing same person in two jurisdictions would mean duplication of the research findings. This is depicted in figure 1. 


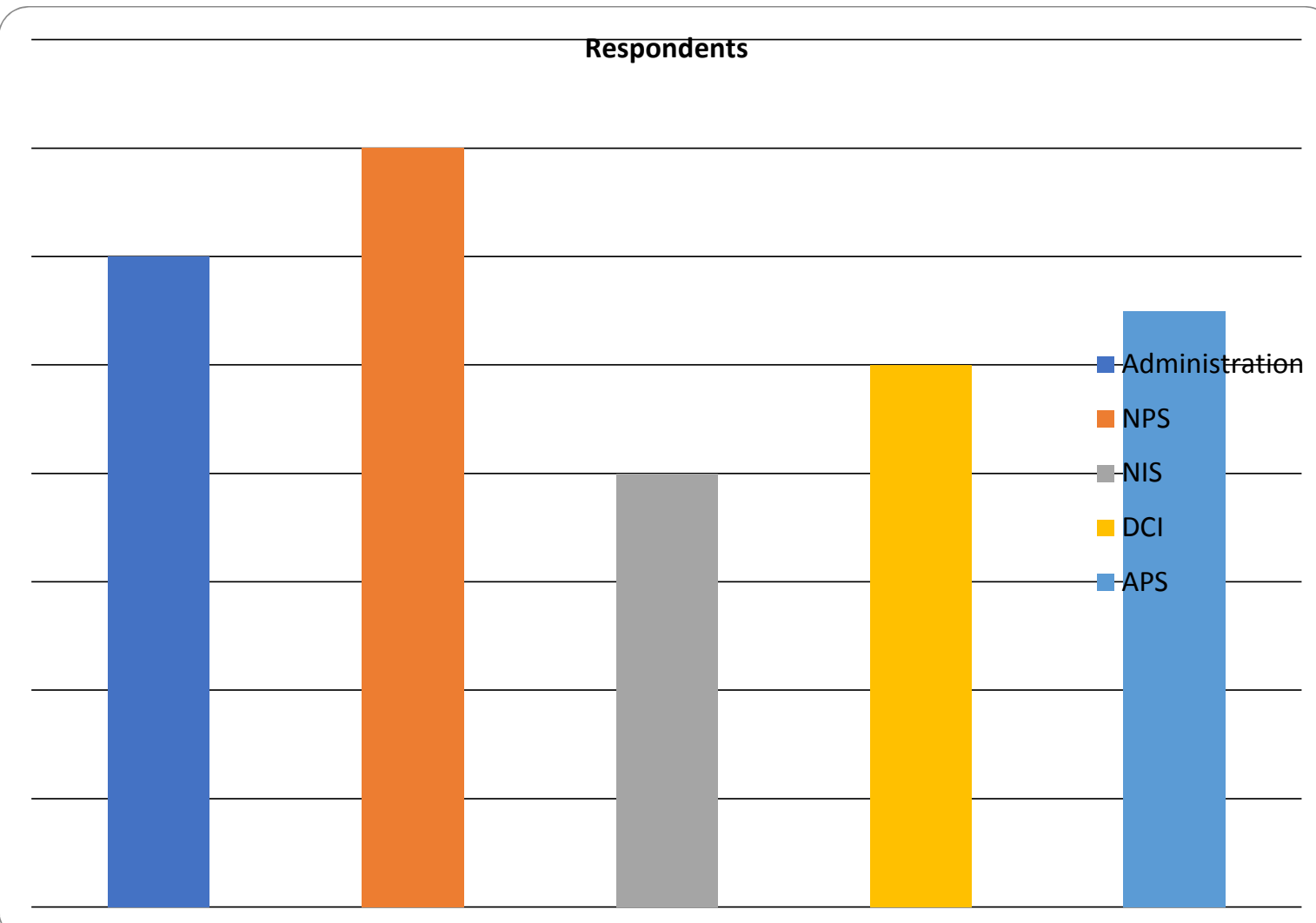

Figure 1: Bar graph showing the Respondents

Source: Data 2020

The bar graph shows a higher response rate from the NPS department followed by the Administrative officers, the APS, DCI and finally the NIS. The lower response rate from the NIS is largely attributed to the fact that while all other departments were well represented in the Sub Counties, an NIS officer could double up to represent the wards and at the same time represent the Sub counties. That is, the staffing is not commensurate to the number of offices anticipated by the researcher.

\subsubsection{Demographic Data of Respondents}

The subjects of this study comprised of National government administrative officers, Kenya Police service, Administration police Service, Directorate of Criminal Investigations and National Intelligence Service offficers randomly selected from the 18 wards of Kirinyaga County. The attributes encompassed variables which included Gender which is an important variable for decision making and communicating the research findings and preferences for interventions, length of service and age which is a variable showing experience level in the security sector and level of education indicating the level of comprehension of the various parameters.

Table 1: Distribution by Gender

\begin{tabular}{|llll|}
\hline & Variable & Frequency & percentage \\
\hline \multirow{2}{*}{ Gender } & Male & 48 & 87 \\
& Female & 7 & 13 \\
& Total & $\mathbf{5 5}$ & $\mathbf{1 0 0}$ \\
\hline
\end{tabular}

\section{Source: Field Data 2020}

In respect to Gender of the respondents, the study revealed that more male were interviewed compared to female. From the respondents $87 \%$ were males while $13 \%$ were female. The implication here is that there were more men than women among the respondents. According to Creta and Macarie (2008), women are underrepresented in Management of public Organizations due to society's beliefs related to the woman's role and that of the man. In Kenya, acceptance of the role played by women in managerial activities is yet to gain roots. This is especially so in Security matters which is largely seen as a man's world. gender. Overall the proportion of male officers in security management cadres is higher than the female counterparts. 


\section{Gender (\%), FemalG,ender (\%)}

$13,13 \%$

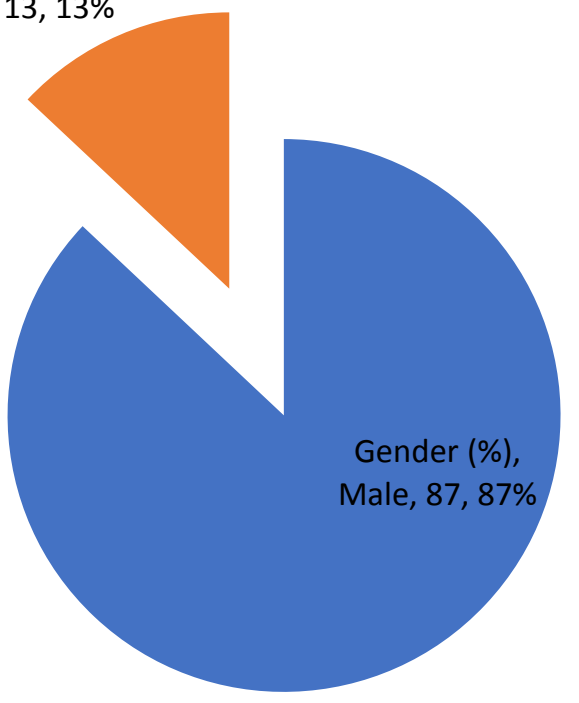

\section{Figure 2 : Respondents by Gender}

\section{Source: Field Data 2020}

The Pie chart shows the proportion of Male respondents being higher than that of women. This parameter was used to take care of the patriachal nature in which the law enforcement agents is assumed to be. This would affect the objectives in the sense that its a information relayed depends on the gender of those involved especially in matters concerning security. This is in conformity to the figures at the National Police Service data base where the number of male officers in managerial positions and who are actively engaged in crime control tend to be higher than the female counterparts.

\section{Table 2: Distribution by Length of Service}

Length of service

\begin{tabular}{|c|c|c|c|c|}
\hline \multicolumn{2}{|c|}{ Respondents } & \multicolumn{2}{|c|}{ Percentage $(\%)$} & \\
\hline $0-5$ years & 0 & & 0 & \\
\hline $6-10$ years & & 5 & & 9 \\
\hline $11-15$ years & & 21 & & 38 \\
\hline Above 15 years & 29 & & 53 & \\
\hline Total & & 55 & & 100 \\
\hline
\end{tabular}

\section{Source: Field Data 2020}

The study realized that majority of the respondents had a service of above 15 years. This category accounted for $53 \%$. Those between 11-15 years of service accounted for 38\%, betweeb $6-10$ years had $9 \%$ while those below five years accounted for $0 \%$. The indication here is that management of criminal intelligence in Kenya is entrusted to officers with some reasonable length of service as opposed to those with less experience in the service. The Intelligence management committees was noted to comprise of personel who have had some stinct in the office. Those regarded to have a shorter period of service apparently did not participate in the management of intelligence while it emerged to be a preserve for those with some longer length of service.

The bar graph below depicts the findings as the length of service; 


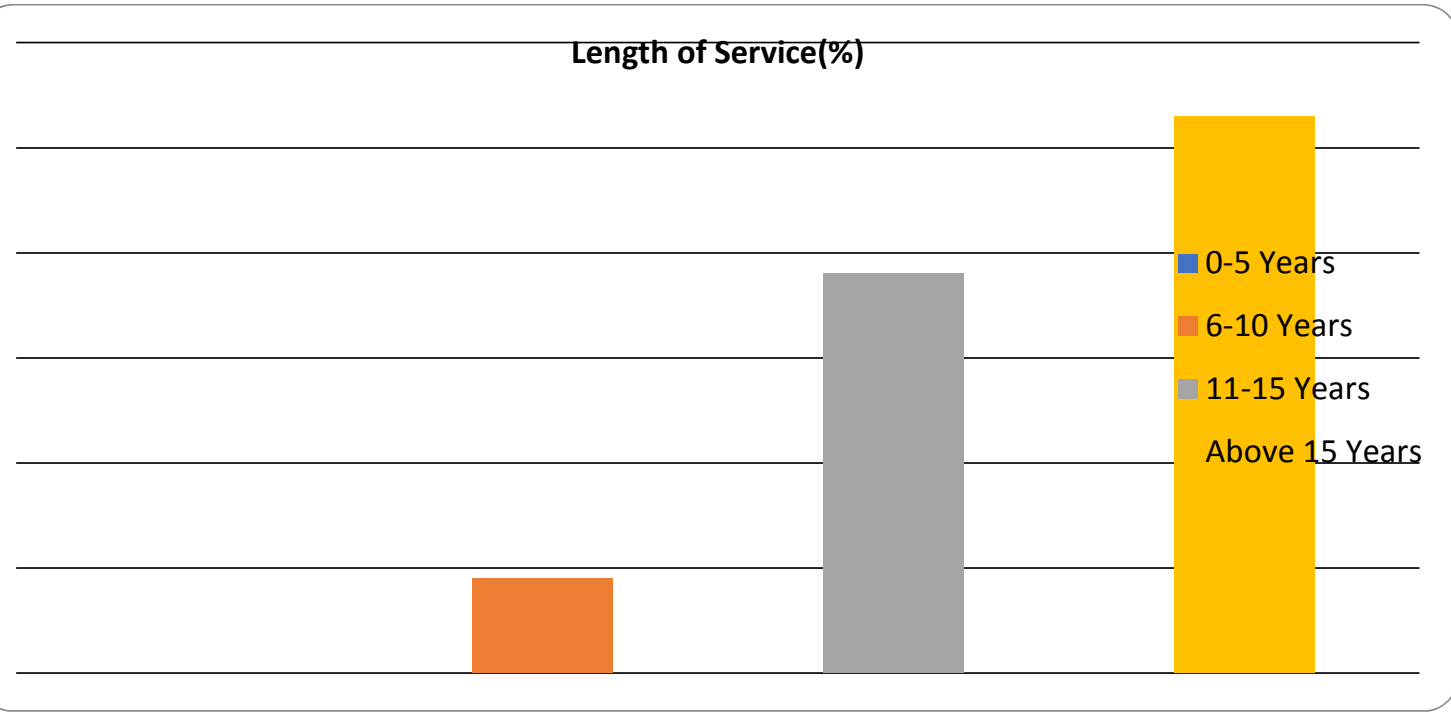

Figure 3: Bar graph showing Length of service

Source: Field Data 2020

The bar graph shows majority of the respondents have a length of service above 15 years followed by those with a service of 11- 15 years and then 6-10 years. None of the respondents was in the range of 0-5 years service. Intelligence management being a managerial function, it is difficult for one to ascend to the positions in the Kenyan set up where career advancement gives prominence to the years of service among other factors.

Table 3: Distribution by Age

Age category

\begin{tabular}{lcc} 
& Respondents & Percentage(\%) \\
$18-25$ & 0 & 0 \\
$26-35$ & 5 & 9 \\
$36-45$ & 23 & 42 \\
Above 45 & 27 & 49 \\
\hline Total & $\mathbf{5 5}$ & $\mathbf{1 0 0}$ \\
\hline
\end{tabular}

\section{Source: Field Data 2020}

The Study found out that most of the respondents were those above the age of 45 . They comprised of $49 \%$ followed by those between the age of 36-45 with $42 \%$, those in the ages of $26-35 \%$ had $9 \%$ while those between the age of $18-25$ were $0 \%$. This indicates that majority of those interviewed were of mature age as opposed to young ones. This information resonates perfectly well with that regarding the length of service. In the Kenyan security sector, the length of service tends to go hand in hand with one's age. Majority of those entrusted with managing security intelligence information are those with longer years of service and subsequently age.

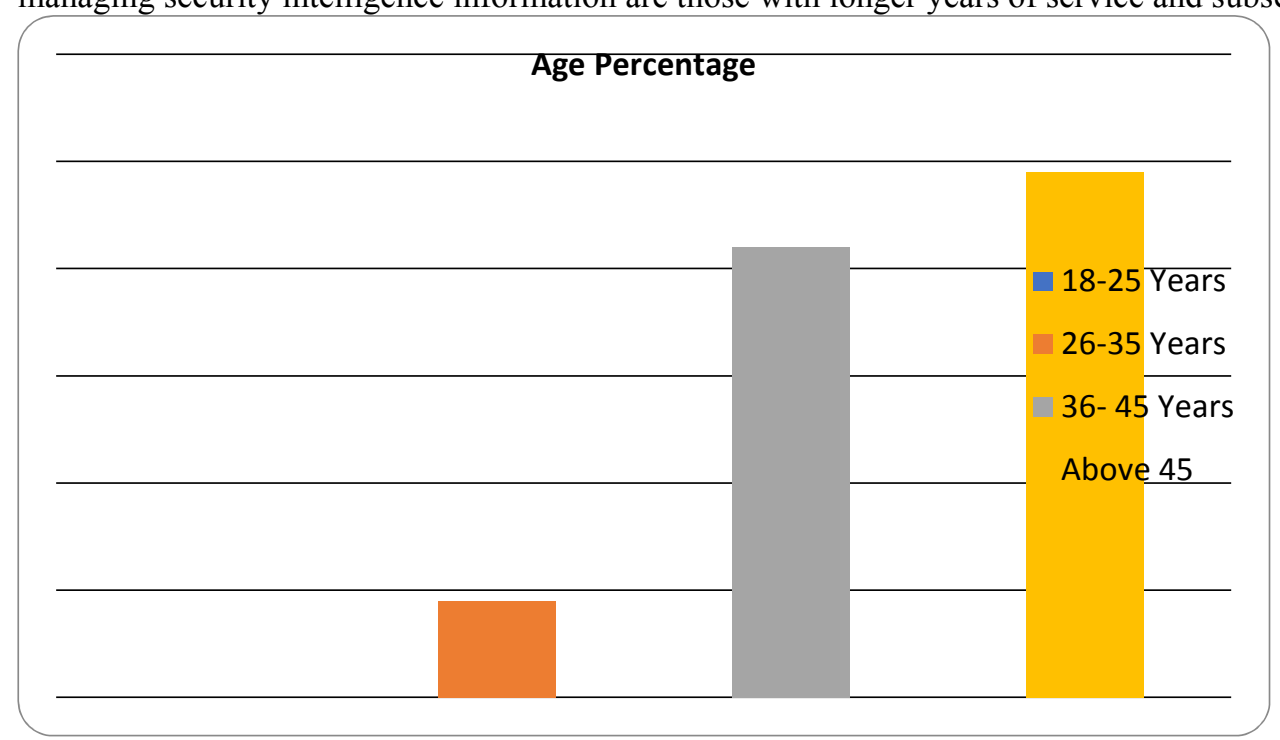

Figure 4: Bar graph showing Age of Respondents

Source: Field Data 2020 
The bar graph depicts a similar trend as witnessed in the length of service. Age is usually regarded as a factor in occupation of public offices in Kenya. Therefore, majority of the respondents are above 45 years who occupy the offices involved in management of Criminal intelligence. This is compared to none of the respondents within the age bracket of 18-25 years which is usually the age where people are recruited in the security service and are deemed to have inadequate knowledge to hold managerial positions.

\section{Table 4: Distribution by Level of Education}

Level of Education

\begin{tabular}{lllll} 
& \multicolumn{2}{c}{ Respondents } & \multicolumn{2}{l}{ Percentage(\%) } \\
Primary & 0 & 43 & 0 & 78 \\
Secondary & & 43 & 16 & \\
Bachelors degree & 9 & & 6 & \\
Masters degree & 3 & & & $\mathbf{1 0 0}$ \\
\hline Total & $\mathbf{5 5}$ &
\end{tabular}

In respect to the level of Education, 78\% were Secondary Education holders, $16 \%$ had Bachelor's degree in diverse fields, $6 \%$ held Post graduate certificates in various fields while $0 \%$ held Primary level education. This was a clear indication that all the respondents were literate which was an important aspect in giving the responses acquired. The sampled population revealed that $100 \%$ had formal schooling and could subsequently understand the questionnares and interview questions thereby giving informed responses which contributed to reliability of the findings.

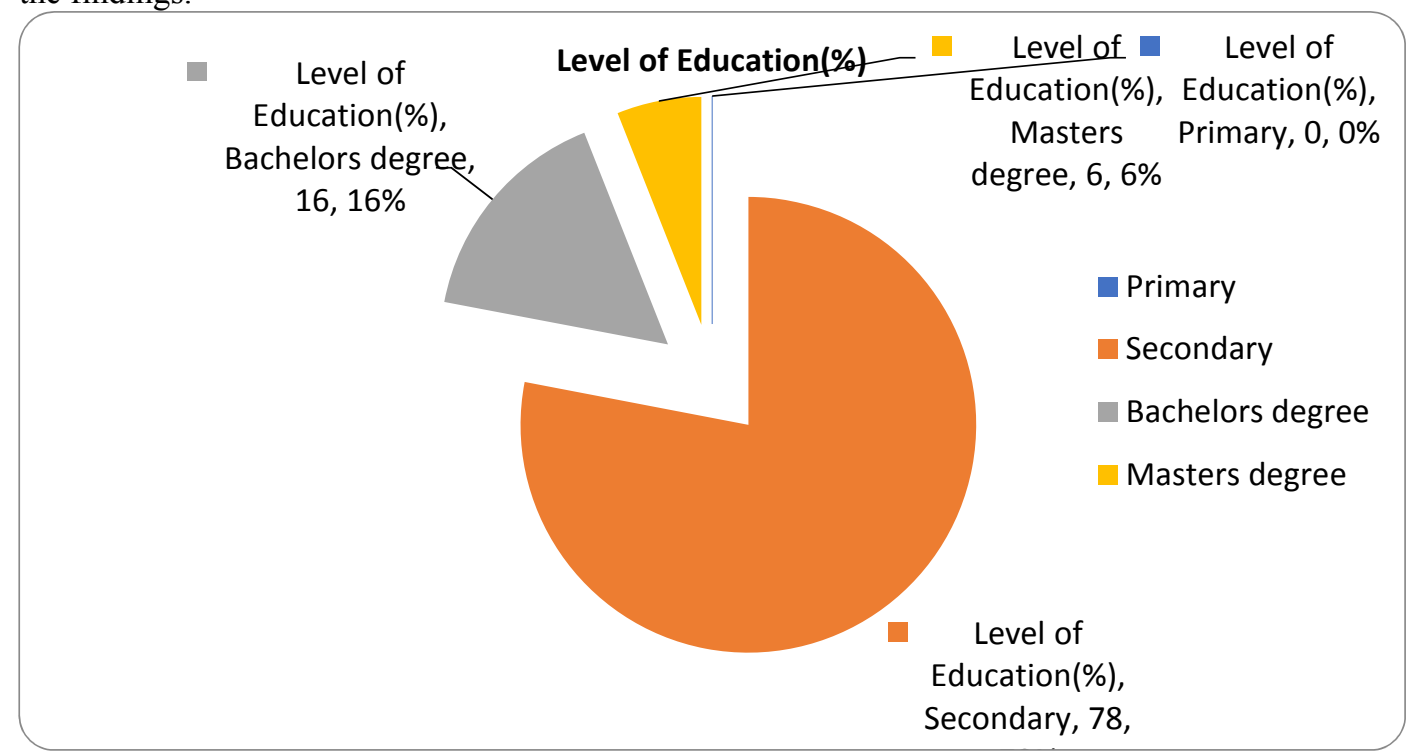

Figure 5: Pie Chart showing Respondents Level of Education

Source: Field Data 2020

The above pie chart shows the level of Education of the respondents. The larger proportion represnts those with Secondary school qualification, followed by Bachelors degree holders and Masters degree holders. None of the respondents was in Primary school education level. This gave a perfect combination for the researcher to get diverse views from different levels of comprehension.

\subsubsection{Extent to Which Integrated Criminal Intelligence Management System are Used in Kenya.}

This study sought to determine the extent to which integrated criminal intelligence system is used in Kenya. To address this objective, it was necessary to understand various components that give rise to an integrated criminal intelligence management system. As such, the researcher sought to establish the role of Criminal intelligence in law enforcement, the process of intelligence collection plan, intelligence process and storage system and managing the disseminated criminal intelligence output. This informed the basis upon which the questionnare was structured to understand these components. 
Table 5: Extent of Integrated Criminal Management System in Kenya

\begin{tabular}{|c|c|c|c|c|c|c|}
\hline $\begin{array}{l}\text { Criminal intelligence is a key element to } \\
\text { effective law enforcement }\end{array}$ & $\begin{array}{l}\text { Agree } \\
55\end{array}$ & $\begin{array}{r}\% \\
100 \%\end{array}$ & $\begin{array}{l}\text { Not } \\
\text { Sure } \\
0\end{array}$ & $0 \%$ & $\begin{array}{l}\text { Disagree } \\
0\end{array}$ & $0 \%$ \\
\hline $\begin{array}{l}\text { In Kenya the intelligence collection plan } \\
\text { include the information categories (open, } \\
\text { closed and classified). }\end{array}$ & 52 & $94.50 \%$ & 0 & $0 \%$ & 3 & $5.50 \%$ \\
\hline $\begin{array}{l}\text { Collected information or intelligence is } \\
\text { transfered into a storage system that has } \\
\text { restricted access }\end{array}$ & 34 & $61.80 \%$ & 15 & $27.20 \%$ & 6 & $11 \%$ \\
\hline $\begin{array}{l}\text { The capture of intelligence material and the } \\
\text { methods used are properly controlled in Kenya }\end{array}$ & 15 & $27.20 \%$ & 12 & $21.80 \%$ & 28 & $51 \%$ \\
\hline $\begin{array}{l}\text { Disseminated intelligence does not guide law } \\
\text { enforcement agencies in effective management } \\
\text { of resources and budget for crime prevention. }\end{array}$ & 37 & $67.20 \%$ & 6 & $11 \%$ & 12 & $21.80 \%$ \\
\hline
\end{tabular}

\section{Source: Field Data 2020}

All the respondents $55(100 \%)$ knew what criminal intelligence is and agreed that it is a key strategy to effective law enforcement. On the other had 52 respondents $(94.5 \%)$ were privy to the fact that intelligence collection plan in kenya entails the open, closed and classified where information is released on need to know basis. This is opposed to only 3 respondents $(5.5 \%)$ who seemed to disagree on the existence of the classification system. This was attributed to lack of practice based on the existing set intelligence system set up. On the aspect of the stoarage of intelligence material, $34(61.8 \%)$ of the respondents agree that it has restricted access while 6 $(11 \%)$ disagree on the same while $15(27.2 \%)$ were not sure of whether the system had restricted access. As to whether the capture of intelligence and methods used are controlled; $28(51 \%)$ respondents disagreed, $15(27.2 \%)$ agreed and other $12(21.8 \%)$ were not sure as to the processes involved. Finally, as to whether the disseminated intelligence aids in resource allocation $37(67.2 \%)$ do not agree if the process impacted on resource allocation, 12 $(21.8 \%)$ felt that it impacts on the resource allocation and $6(11 \%)$ were not sure of how the resources are allocated. This is in line with ratcliffe's assertion that intelligence output should be able to influence decision makers who in return design policies which impact on criminal environment. The bar graph below shows the correlation of indicators showing the extent to which Criminal management system is integrated in Kenya.

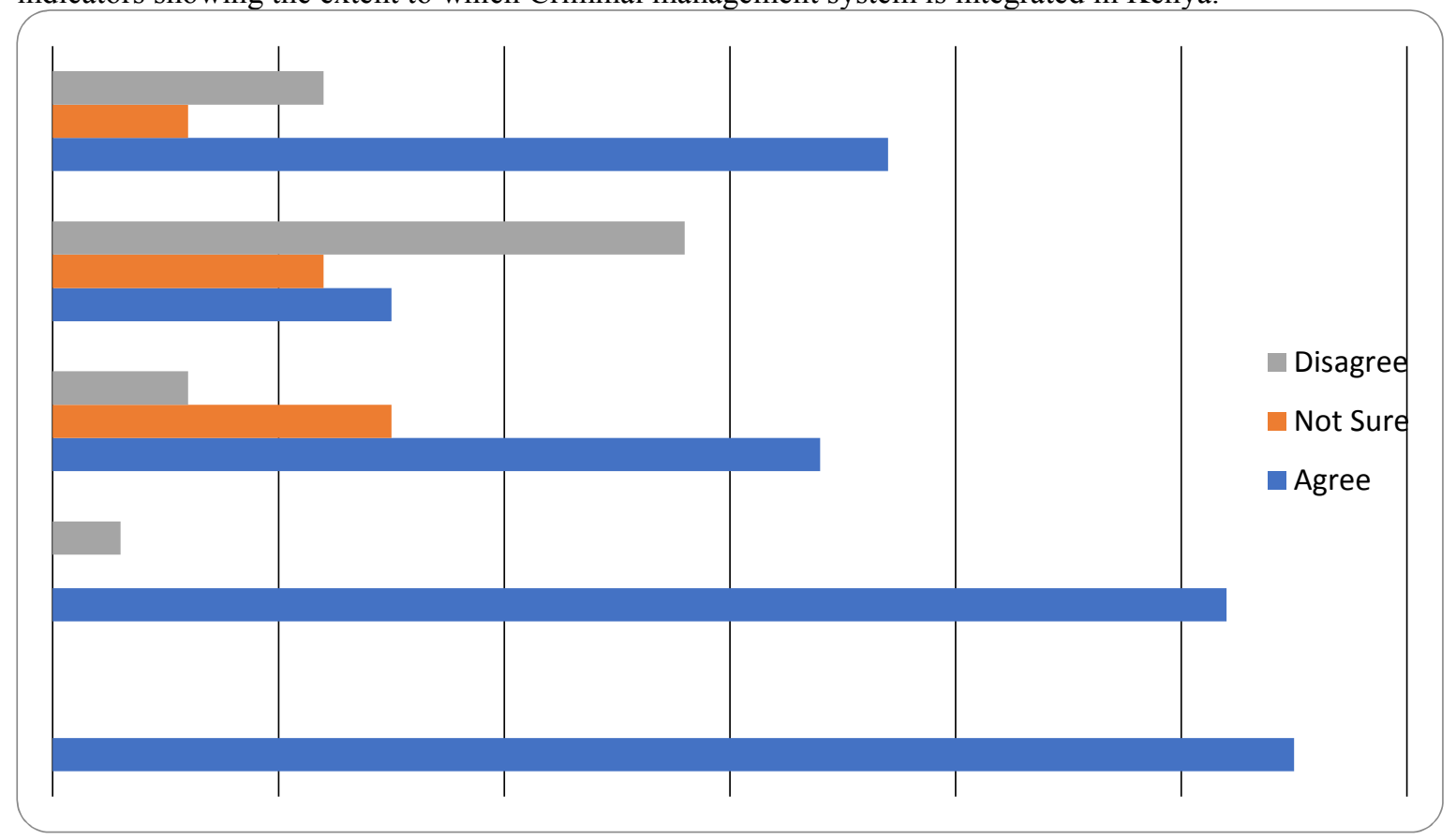

Figure 6: Combined Bar graph showing the Extent of Criminal Intelligence Management in Kenya Source: Field Data 2020

The above information was collaborated through the interview schedule with most of those sampled agreeing that Criminal intelligence is an integral part of crime management. However, it was not clear from majority of 
those sampled the how the process of gathering information is undertaken. There was lack of clarity as to who determined the information targeted for the intellegince and what kind of information was specific for strategic or operational purposes. The respondents had a general feeling that since they are not included in the determination of the intelligence needs to be undertaken, they need not be part of its implementation. The respondents felt that as long as the system of determining the type of data as well as sources remained a secret, then it would be difficult to classify the information.

\subsection{Conclusion}

In conclusion, criminal intelligence is such an integral part of managing security in Kenya. It is through criminal intelligence that law enforcers are able to fight crime in a proactive manner. It helps in identifying criminals and criminal trends thereby enabling forecast and targets for investigation at operation level. Moreso, intelligence aids in budgeting and managing resources at the strategic level. All these calls for various processes and units that require to work in partnership so as to create harmony. This therefore calls for lots of control processes, accountability of all those involved in managing the intelligence system and all the related procedures and processes. This is the basis upon which this research was anchored.

\subsection{Recommendation}

The research acknowledges the fact that management of criminal intelligence is a product of so many factors. Some of these factors relate to policy and rule of pracitce. Based on the research findings, the following recommendations can be made;

i. Develop Criminal intelligence management sharing plan which details information gathering, analysis and disemmination. Such a plan goes a long way towards improving information gathering, analysis to disemminate information of value and that is actionable in a timely manner.

ii. To adequately vet and train officers to boost their intelligence capability. This aids in developing sense of teamwork anmongst agencies in acquiring relevant information to address security concerns.

iii. Legislations to be enacted and (or) amended to reduce bureaucracies that hinder timely dissemination of intelligence. This is by reducing the protocols involved in getting the information to the operation teams.

\section{References}

Balzacq, T. (2011) "Constructivism and securitization studies" in The Routledge Handbook of Security Studies (Routledge)

Barry Buzan, Ole Weaver (2012) Security: A new Framework for Analysis, Collins edition, Oxford: Oxford University Press.

Brown, S. D. (2007). The meaning of criminal intelligence. International Journal of Police, Science and management,

Bureau of Justice Assistance, Criminal Intelligence System Operating Policies (28 Code of Federal Regulations Part 23.20). 1993.

California Department of Justice, The Bureau of Intelligence Operations Manual. 1993.

Carter, D. L. and T. Martinelli. "Civil Rights and Law Enforcement Intelligence. ” The Police Chief, June 2007.

Dixon, B. \& Rauch, J. 2004. Sector Policing: Origins And Prospects. Institute for Security Studies. Monograph No.97. Pretoria: Institute for Security Studies.

Els, W. J. 2000. Crime Intelligence Gathering: Policy Directives and Procedures. Pretoria: South African Police Service.

Estévez, Eduardo E., "Comparing intelligence democratization in Latin America: Argentina, Peru, and Ecuador Cases", Intelligence and National Security, Vol. 29, No. 4 (2014)

Hooper, M.K 2014. Journal of Forensic Research and Crime Studies. Aknowledging Existence of a Fourth Era of Policing: The Information Era. JScholar Publishers: California.

Lowental, David 2015, (2nd edition) The past is aforeign country, Cambridge: Cambridge University Press.

Macarie, F and Creta, S 2018. Eurasian Journal of Social Sciences 3 (2), 16-23.

Ratcliffe, J.H. and Taniguchi, T. A. (in press) 2004 "Is crime higher around drug - gang street corners? Two spatial approaches to the relationship between gang set spaces and local crime levels". Crime Patterns and Analysis, Vol 1, Issue 1.

Ratcliffe, Jerry (Ed.) (2009): Strategic Think bin Criminal Intelligence. The Federation Press, London.

Sheldon, R. M. 2011. The Intelligencer: Journal of US Intelligence Studies. A Guide To Intelligence From Antiquity to Rome. Virginia, USA: Association of Former Intelligence Officers.

Schneider, S. R. 2009. The Criminal Intelligence Function: Toward a Comprehensive and Normative Model. International Association of Law Enforcement Intelligence Analysts Journal.

UNODC, (United Nations office on Drugs and Crime), Police Information and Intelligence Systems, in Criminal justice assessment toolki, (New York: United Nations, 2011). 